\title{
LOS OBSTÁCULOS DE LA CONSTITUCIÓN MEXICANA: UN “AUTORITARISMO DEMOCRÁTICO”
}

\author{
THE OBSTACLES OF THE MEXICAN CONSTITUTION: \\ A "DEMOCRATIC AUTHORITARIANISM"
}

\section{OS OBSTÁCULOS DA CONSTITUIÇÃO MEXICANA: UM "AUTORITARISMO DEMOCRÁTICO"}

\author{
MANUEL ÁNGEL RODRÍGUEZ EDEZA \\ https://orcid.org/0000-0002-2537-8339 / maredezasinaloa@hotmail.com \\ Universidad Autónoma de Occidente. \\ México.
}

\begin{abstract}
RESUMO
Este ensaio tenta explicar o sistema político mexicano "compreendendo" sua Constituição. É um cinismo realista, em face de um dos sistemas autoritários, mais autoritários e longevos que tem sido capaz de confundir cientistas políticos, sociólogos, economistas e historiadores, mantendo-se como a "ditadura perfeita", diria Mario Vargas Llosa em 1990. A ideia é, no que diz respeito aos indicadores de qualidade democrática propostos por Diamond e Morlino, procurar-se experimentar "Democracia mexicana" submetendo-a e "adaptando-a" a uma análise crítica. No final, podemos ver o "autoritarismo mexicano", disfarçado em um constitucionalismo presidencialista ou "metaconstitucionalismo" (Carpizo, 1978), que se baseia até mesmo na conformação mesmo da Constituição.
\end{abstract}

Palavras-chave: México, autoritarismo, Constituição.

\begin{abstract}
The present essay tries to explain the Mexican political system "understanding" its Constitution; is a realistic cynicism, against one of the sustained authoritarian systems and of a longer life that has been able to confuse political scientists, sociologists, economists and historians, maintaining itself as the "perfect dictatorship," Mario Vargas Llosa would say in 1990. The idea is, with regard to the indicators on democratic quality proposed by Diamond and Morlino, 2004, to experience the "Mexican democracy" subjecting it and "adapting" it to a critical analysis. We can see the "Mexican authoritarianism", disguised in a presidential constitutionalism or "metaconstitutionalism" (Carpizo, 1978), that rests even from the own conformation of the Constitution.
\end{abstract}

Keywords: Mexico, authoritarianism, Constitution.

\begin{abstract}
El presente ensayo intenta explicar el sistema político mexicano "comprendiendo" su Constitución. Es un cinismo realista, frente a uno de los sistemas autoritarios sostenidos y de más larga vida que ha podido confundir a politólogos, sociólogos, economistas e historiadores, manteniéndose como la "dictadura perfecta", diría Mario Vargas Llosa en 1990. La idea es, a propósito de los indicadores que sobre calidad democrática propusieran Diamond y Morlino, se busca experimentar la "democracia mexicana" sometiéndola y "adaptándola" a un análisis crítico. Al final, se puede constatar el "autoritarismo mexicano", disfrazado en un constitucionalismo presidencial o “metaconstitucionalismo" (Carpizo, 1978), que descansa incluso desde la conformación misma de la Constitución.
\end{abstract}

Palabras clave: México, autoritarismo, Constitución. 


\section{SUMARIO}

INTRODUCCIÓN; 1 CONSIDERACIONES TEÓRICAS Y METODOLÓGICA;1.1 Respecto al procedimiento; 1.2 Respecto al contenido; 1.3 Respecto al resultado; 2 IMPERIO DE LA LEY; 3 DE LOS PODERES Y SU ELECCIÓN (RESPONSABILIDAD ELECTORAL Y COMPETENCIA ELECTORAL); 4 DE LAS COMPETENCIAS: "PESOS Y CONTRAPESOS" (LA RESPONSABILIDAD INTERINSTITUCIONAL).; 5 DE LA INSEGURIDAD, SU COMBATE Y "LA CORRUPCIÓN"; 6 DEL SISTEMA NACIONAL "ANTICORRUPCIÓN" Y EL MEJORAMIENTO DE LA DEMOCRACIA; CONCLUSIONES; REFERENCIAS.

\section{PRESENTACIÓN}

En 2003, Robert Dahl se preguntaba: ¿Es democrática la Constitución de los Estados Unidos? Sin conocer en ese momento su obra, debido a un trabajo posterior de Diamond y Morlino (2004), donde plantean la conveniencia de medir las democracias en su calidad, surgió la idea de "cruzar" o medir la democracia mexicana desde su Constitución, ya que como se ha señalado en trabajos anteriores (Rodríguez Edeza, 2017 y 2018), primero que nada la democracia tendrá que ser legal o constitucional.

\section{INTRODUCCIÓN}

Mucho se ha discutido las distorsiones democráticas de la Constitución Mexicana en cuanto a sus clausulados y redacción, con facultades "metaconstitucionales" (Carpizo, 1978) que se le otorgan al Presidente en turno, en el entendido, no obstante, que un régimen presidencial la preeminencia es del ejecutivo. Pero la intención estuvo implícita desde el principio, para contener las "tentaciones" de un Parlamento que dificultaba el "buen orden" y funcionamiento de la República (Cosío, 1973, Krauze, 1994).

Posteriormente, la creación de un partido “a modo”, con ropajes hegemónicos (Sartori, 2000), le permitió generar facultades aún más predominantes y actuar de manera avasalladora sobre los otros poderes de la "Unión", en un aparente escenario democrático y una dictadura perfecta, diría Mario Vargas Llosa (1990).

Pero, ¿cuáles son esos clausulados “metaconstitucionales” del Presidente o la Presidencia de México? ¿Cómo logra mantener una aparentemente “democracia” en una dictadura? ¿Qué se puede hacer al respecto?

La intención del presente artículo es intentar entender la Constitución Mexicana y escudriñar ese andamiaje ponderándolo democráticamente y, hasta dónde es posible, aceptable o modificable. Para ello y, a propósito del boom que sobre calidad democrática se ha dado en 
los últimos años, apoyándonos en las dimensiones que para tal efecto señalan Diamond y Morlino, 2004; Morlino, 2007, 2008 y Alcántara, 2008, a saber: imperio de la ley, responsabilidad electoral, responsabilidad interinstitucional, participación, competitividad partidaria, libertad, igualdad y resultados, hacer un análisis de los articulados de la Constitución Mexicana, leyes secundarias y otras normatividades, "adaptándola" a grandes dimensiones y contrastándolas para su conclusión.

\section{CONSIDERACIONES TEÓRICAS Y METODOLÓGICA}

En el 2003, Roberth Dhal, en su obra, ¿Es democrática la Constitución de los Estados Unidos?, cuestionó la democracia constitucional de los Estados Unidos, sobre todo a partir de la polémica elección presidencial de 2000, donde George Bush, hijo, resultó electo Presidente no obstante que su competidor, Al Gore, había obtenido el mayor número popular de votos ya que la constitución de los Estados Unidos reconoce, en su vigésima segunda enmienda, a los votos electorales, como los que cuentan para el resultado final. Es decir, Dahl, no cuestiona la democracia original de los Estados Unidos, pero sí la conveniencia o no, de un ajuste constitucional, para una nueva realidad.

En otro documento, Diamond y Morlino, 2004, sugieren la calidad democrática, partiendo de 8 dimensiones, en tres ejes diferenciados referidos al procedimiento, el contenido y los resultados:

\subsection{Respecto al procedimiento}

Estado de derecho o imperio de la ley: en este punto, citando a O'Donnell (Diamond y Morlino, 2004), los autores refieren a esta dimensión como la base de todas las demás; el imperio de la ley o regla de la ley, es aquella donde todos los ciudadanos son iguales ante la ley, la cual es confiable, consistente y aplicada por un poder judicial independiente. Del conocimiento público, universal, estables y no retroactivas.

Participación: un régimen puede ser democrático, señalan, sólo si garantiza los mecanismos para la participación política y los derechos de todos los ciudadanos en edad de participar. No sólo votando, sino en todas las formas legales de participación. Partidos políticos, organizaciones civiles, manifestaciones, protestas, exigencias a la autoridad y monitoreo. 
Competencia: normal, libre y confiable para todos los partidos políticos; con reglas que satisfagan su lucha legítima por el poder; electoral, en los medios de información y el financiamiento.

Rendición de cuentas vertical: la posibilidad de que el electorado pueda sancionar a su autoridad depende de la información, la justificación y la pena a esa actuación; generalmente es en la elección donde esa accontability se concretiza, pero el proceso debe ser permanente con el ciudadano, la transparencia y rendición de cuentas en la actualidad, son mecanismos que pueden ayudar a ese proceso, algunas otras formas de democracia directa podrían ser consideradas, más los representantes, líderes de partidos y actores políticos, tienen la obligación de mantenerlo activo y vigente.

Rendición de cuentas horizontal: pero la rendición de cuentas no sólo debe ser con el ciudadano; mecanismos interinstitucionales entre poderes e instancias deben ser creados para mantener "balances y contrapesos" y una transparencia en la actuación y rendición de cuentas de y entre instituciones, dar seguimiento y fiscalizar su operación.

\subsection{Respecto al contenido}

Libertad: consistente básicamente en tres tipos de derechos: políticos, civiles y sociales (económicos sociales). Políticos, para votar, para elegir y ser elegido. Civiles para las libertades de ideología, expresión, información, religión, organización y asociación y sociales o económicas sociales, no sólo para la propiedad privada, sino el empleo y la negociación.

Igualdad: en esa libertad y esos derechos. La igualdad política y legal de todos sus ciudadanos. No necesariamente material o económica, sino sustantiva, esto es de posibilidades a la educación, la salud, el empleo, protección, vivienda.

\subsection{Respecto al resultado}

Resposiveness (o resultados): de satisfacción con la democracia y su legitimación.

Lo que se pretende, es confrontar en parte esas dimensiones, con algunas dimensiones o articulados de la Constitución, para observar su correspondencia democrática; no sólo para la crítica, sino para viabilizar el "ideal democrático", que si bien es cierto, en lo general se ha empezado a discutir y discernir (Rodríguez Edeza, 2017 y 2018), es importante para su 
mantenimiento, adecuación y/o modificación. Es necesario resaltar, que es una adaptación, un esfuerzo de aproximación y contraste para la crítica, por el propósito del artículo y el espacio, para efecto de un trabajo más detallado de cada una de las dimensiones ver otro trabajo del autor (Rodríguez Edeza, 2018).

\section{IMPERIO DE LA LEY}

La primera parte o dimensión que se va a observar, tiene que ver con lo que los autores llaman, el Imperio de la Ley o Estado de Derecho; este apartado, la Constitución mexicana lo reconoce básicamente en los artículos $1^{\circ}, 2^{\circ}, 5^{\circ}, 6^{\circ}$ y $35^{\circ}$. El primero de ellos señala: "En los Estados Unidos Mexicanos todas las personas gozarán de los derechos humanos reconocidos en esta Constitución y en los tratados internacionales de los que el Estado Mexicano sea parte." Quedando prohibidos toda discriminación motivada por origen étnico o racial, el género, la edad, las discapacidades, condición social, condiciones de salud, religión, opiniones, preferencias sexuales, estado civil o cualquier otra que atente contra la dignidad humana y tenga por objeto anular o menoscabar los derechos y libertades de las personas.

El artículo $2^{\circ}$ por su parte dice en su párrafo primero A: “Esta Constitución reconoce y garantiza el derecho de los pueblos y las comunidades indígenas a la libre determinación y, en consecuencia, a su autonomía”. El artículo 5: “A ninguna persona podrá impedirse que se dedique a la profesión, industria, comercio o trabajo que le acomode, siendo lícitos. El ejercicio de esta libertad sólo podrá vedarse por determinación judicial”.

Por su parte, el artículo 35, señala: "son derechos del ciudadano: Votar en las elecciones populares; poder ser votado para todos los cargos de elección popular, asociarse individual y libremente para tomar parte en forma pacífica en los asuntos políticos del país, iniciar leyes y votar en las consultas populares sobre temas de trascendencia nacional".

No obstante, el artículo $6^{\circ}$ ya entraña una primera particularidad, señala: "la manifestación de las ideas no será objeto de ninguna inquisición judicial o administrativa, sino en el caso de que ataque a la moral, la vida privada o los derechos de terceros, provoque algún delito, o perturbe el orden público". Y más adelante apunta: "toda persona tiene derecho al libre acceso a información plural y oportuna, así como a buscar, recibir y difundir información e ideas de toda índole por cualquier medio de expresión”. Para ello, “el Estado garantizará el derecho de acceso a las tecnologías de la información y comunicación, así como a los servicios de radiodifusión y telecomunicaciones, incluido el de banda ancha e internet”. Toda información 
será pública y sólo podrá ser reservada temporalmente por razones de interés público, señalando: "la ley determinará los supuestos específicos bajo los cuales procederá la declaración de inexistencia de la información".

Contará, para tal efecto, con un organismo autónomo especializado, siendo sus resoluciones vinculatorias, definitivas e inatacables. Será integrado por siete comisionados, los cuales, para su nombramiento, la Cámara de Senadores, "previa realización de una amplia consulta a la sociedad", a propuesta de los grupos parlamentarios, con el voto de las dos terceras partes de los miembros presentes, nombrará al comisionado o los comisionados; no obstante, pudiendo ser objetados por el Presidente de la República.

Es decir, el órgano garante, como ellos mismos le llaman, y que pudiera garantizar por en cuanto el derecho inalienable de Trasparencia, Rendición de Cuentas e Información, de entrada, está ya supeditado directamente al Ejecutivo.

Y en materia de comunicación, el otro pilar para la información, señala: el Estado garantizará a la población su integración a la sociedad de la información, prohibiéndose la transmisión de publicidad o propaganda presentada como información periodística o noticiosa. La ley establecerá un organismo público descentralizado con autonomía técnica, operativa, de decisión y de gestión, que tendrá por objeto proveer el servicio de radiodifusión. Dicho organismo contará con un Consejo Ciudadano con el objeto de asegurar su independencia y una política editorial imparcial y objetiva. Siendo, el Presidente del organismo designado, a propuesta del Ejecutivo Federal, con el voto de dos terceras partes de los miembros presentes de la Cámara de Senadores.

Es decir, los órganos garantes de la información y comunicación, están supeditados invariablemente al ejecutivo; se pudiera entender desde el punto de vista de que se está en un régimen presidencial; no obstante, los pesos y contrapesos son importantes aún en democracias presidencialistas.

Más delante, el artículo 29, presenta otra salvedad, dice: en los casos de invasión, perturbación grave de la paz pública, o de cualquier otro que ponga a la sociedad en grave peligro o conflicto, el Presidente, con la aprobación del Congreso de la Unión o de la Comisión Permanente cuando aquel no estuviere reunido, podrá restringir o suspender en todo el país o en lugar determinado el ejercicio de los derechos y las garantías que fuesen obstáculo para hacer frente, rápida y fácilmente a la situación. 


\section{DE LOS PODERES Y SU ELECCIÓN (RESPONSABILIDAD ELECTORAL Y COMPETENCIA ELECTORAL)}

Ahora bien, respecto a la responsabilidad electoral y competencia electoral, que es otro de los puntos tratados por Diamond y Morlino (2004), la constitución mexicana establece: Artículo 41: el pueblo ejerce su soberanía por medio de los Poderes de la Unión, dividiéndose para su ejercicio en Legislativo, Ejecutivo y Judicial (artículo 49). Estos poderes, serán renovados mediante elecciones libres, auténticas y periódicas; los senadores y el Presidente cada 6 años y los diputados cada 3 (para el 2018, por cierto, habrá ya reelección legislativa); para ello: “los partidos políticos son investidos como entidades de interés público y canales de elección y la ley determinará las normas y requisitos para su registro, las formas específicas de su intervención, obligaciones y prerrogativas que les corresponden”, con lo que de algún modo se garantizan elecciones recurrentes, no obstante el problema comienza en la competencia e equidad de la elección.

Se garantizará, señala el mismo artículo, que los partidos cuenten de manera equitativa con elementos para llevar a cabo sus actividades, señalando "las reglas" a que se sujetará su financiamiento y, debiendo garantizar que los recursos públicos prevalezcan sobre los de origen privado. Los partidos políticos nacionales y candidatos independientes tendrán derecho al uso de manera permanente de los medios de comunicación, siendo, el tiempo establecido como derecho de los partidos y, en su caso, de los candidatos independientes, distribuidos entre los mismos conforme a lo siguiente: el setenta por ciento de acuerdo a los resultados de la elección inmediata anterior para diputados federales $\mathrm{y}$, el treinta por ciento restante dividido en partes iguales, para todos, de las cuales, una de ellas podrá ser asignada a los candidatos independientes en su conjunto.

Es decir, queda totalmente claro la inequidad del reparto; pues mientras los que ganan, se les dan más prioridades de que permanezcan en la lucha; prácticamente los pequeños, o candidatos independientes, están condenados a desaparecer. No sólo porque se llevan apenas un $30 \%$ de los recursos disponibles, sino porque estos aún, deben ser compartidos con los grandes. Lo que los hace, aún más vulnerables.

Por otra parte, el citado artículo, señala: "a cada partido político nacional sin representación en el Congreso de la Unión se le asignará para radio y televisión solamente la parte correspondiente al porcentaje igualitario" y además, “los partidos políticos y los 
candidatos en ningún momento podrán contratar o adquirir, por sí o por terceras personas, tiempos en cualquier modalidad de radio y televisión".

El Instituto Nacional Electoral será el organismo público, en la materia, autónomo, dotado de personalidad jurídica y patrimonio propio, en cuya integración participarán el Poder Legislativo de la Unión, los partidos políticos nacionales y los ciudadanos. Contará en su estructura con órganos de dirección, ejecutivos, técnicos y de vigilancia, siendo su Consejo General su órgano superior de dirección y se integrará por un consejero Presidente y diez consejeros electorales y, concurrirán, con voz pero sin voto, los consejeros del Poder Legislativo, los representantes de los partidos políticos y un Secretario Ejecutivo, todo parece normal hasta ahí, no obstante, como en el susodicho órgano garante, al señalar su conformación dice: el consejero Presidente y los consejeros electorales, serán electos por el voto de las dos terceras partes de los miembros presentes de la Cámara de Diputados, mediante el siguiente procedimiento:

La Cámara de Diputados emitirá el acuerdo para la designación de un comité técnico de evaluación, integrado por siete personas de reconocido prestigio, de las cuales tres serán nombradas por el órgano de dirección política de la Cámara DE Diputados, dos por la Comisión Nacional de los Derechos Humanos (que nombran también los diputados) y tres por el organismo garante establecido en el artículo $6^{\circ}$ de la Constitución, que como ya vimos, está a la decisión o veto del Presidente de la República.

Ahora bien, algo que podría pasar desapercibido es que, dentro de las funciones del Instituto (Electoral), está además, la demarcación territorial de los distritos electorales en el país y con las modificaciones recientes, no solo tendrá injerencia en las elecciones federales, sino también en las locales.

\section{DE LAS COMPETENCIAS: “PESOS Y CONTRAPESOS” (LA RESPONSABILIDAD INTERINSTITUCIONAL).}

Ahora bien, respecto a la responsabilidad interinstitucional, de pesos y contrapesos, la Constitución señala: artículo 49: "no podrán reunirse dos o más de los Poderes en una sola persona o corporación, ni depositarse el Legislativo en un individuo, salvo el caso de facultades “extraordinarias” al Ejecutivo de la Unión”. La Administración Pública Federal será centralizada y paraestatal (artículo 90). Los estados adoptarán, para su régimen interior, la forma de gobierno republicano, representativo, democrático, laico y popular, teniendo como base de su 
división territorial y de su organización política y administrativa, el municipio libre, conforme a las bases siguientes (Artículo 115).

Cada Municipio, será gobernado por un Ayuntamiento de elección popular directa, integrado por un Presidente Municipal y el número de regidores y síndicos que la ley determine. (No obstante), las Legislaturas locales, por acuerdo de las dos terceras partes de sus integrantes, podrán suspender ayuntamientos, declarar que éstos han desaparecido y suspender o revocar el mandato a alguno de sus miembros.

Los municipios estarán investidos de personalidad jurídica y manejarán su patrimonio conforme a la ley y tendrán a su cargo las funciones y servicios públicos siguientes:

a) Agua potable, drenaje, alcantarillado, tratamiento y disposición de sus aguas residuales;

b) Alumbrado público.

C) Limpia, recolección, traslado, tratamiento y disposición final de residuos;

d) Mercados y centrales de abasto.

e) Panteones.

f) Rastro.

g) Calles, parques y jardines y su equipamiento;

h) Seguridad pública, en los términos del artículo 21 de esta Constitución, policía preventiva municipal y tránsito; e

i) Los demás que las Legislaturas locales determinen según las condiciones territoriales y socio-económicas de los Municipios, así como su capacidad administrativa y financiera.

Podrán, previo acuerdo entre sus ayuntamientos, coordinarse y asociarse para la más eficaz prestación de los servicios públicos o el mejor ejercicio de las funciones que les correspondan (no obstante), en este caso y tratándose de la asociación de municipios de dos o más Estados, deberán contar con la aprobación de las legislaturas de los Estados respectivas.

Por su parte, los Estados, no podrán, en ningún caso (artículo 117): celebrar alianza, tratado o coalición con otro Estado ni con las Potencias extranjeras (Sic); acuñar moneda, emitir papel moneda, estampillas ni papel sellado. Gravar el tránsito de personas o cosas que atraviesen su territorio. Prohibir ni gravar directa ni indirectamente la entrada a su territorio, ni la salida de él, a ninguna mercancía nacional o extranjera. Gravar la circulación ni el consumo de efectos nacionales o extranjeros, con impuestos o derechos cuya exención se efectúe por aduanas locales, requiera inspección o registro de bultos o exija documentación que acompañe la mercancía. Expedir ni mantener en vigor leyes o disposiciones fiscales que importen 
diferencias de impuesto o requisitos por razón de la procedencia de mercancías nacionales o extranjeras, ya sea que esta diferencia se establezca respecto de la producción similar de la localidad, o ya entre producciones semejantes de distinta procedencia. Contraer directa o indirectamente obligaciones o empréstitos con gobiernos de otras naciones, con sociedades o particulares extranjeros, o cuando deban pagarse en moneda extranjera o fuera del territorio nacional.

Tampoco, pueden (artículo 118), sin consentimiento del Congreso de la Unión: Establecer derechos de tonelaje, ni otro alguno de puertos, ni imponer contribuciones o derechos sobre importaciones o exportaciones. Tener, en ningún tiempo, tropa permanente ni buques de guerra, y Hacer la guerra por sí a alguna potencia extranjera, exceptuándose los casos de invasión y de peligro tan inminente que no admita demora. En estos casos darán cuenta inmediata al Presidente de la República.

Y señala, los Poderes de la Unión tienen el deber de proteger a las entidades federativas contra toda invasión o violencia exterior (artículo 119). En cada caso de sublevación o trastorno interior, les prestarán igual protección, siempre que sean excitados por la Legislatura de la entidad federativa o por su Ejecutivo, si aquélla no estuviere reunida. "Estando obligadas a entregar sin demora a los imputados o sentenciados, así como a practicar el aseguramiento y entrega de objetos, instrumentos o productos del delito", atendiendo a la autoridad de cualquier otra que los requiera. Quedando, los titulares de los poderes ejecutivos de las entidades federativas obligados a publicar y hacer cumplir las leyes federales (artículo 120).

Respecto al poder judicial, que Diamond y Morlino (2004) señalan, como el más importante para garantizar el Estado de Derecho o Imperio de la Ley, al mismo tiempo los pesos y contrapesos de los que hablamos, el artículo 94 establece: "se deposita el ejercicio del Poder Judicial de la Federación en una Suprema Corte de Justicia, en un Tribunal Electoral, en Tribunales Colegiados y Unitarios de Circuito y en Juzgados de Distrito". Los Ministros de la Suprema Corte de Justicia durarán en su encargo quince años, y para nombrarlos, artículo 96, el Presidente someterá una terna ( $\mathrm{y}$ no a la inversa, como ocurre en algunos otros países) a consideración del Senado, el cual, previa comparecencia de las personas propuestas, designará al Ministro que deba cubrir la vacante. Pero además se señala, la designación se hará por el voto de las dos terceras partes de los miembros del Senado presentes, dentro del improrrogable plazo de treinta días. Si el Senado no resolviere dentro de dicho plazo, ocupará el cargo de Ministro la persona que, dentro de dicha terna, designe el Presidente de la República. 
Para no dejar lugar a dudas, apunta, "en caso de que la Cámara de Senadores rechace la totalidad de la terna propuesta, el Presidente de la República someterá una nueva, en los términos del párrafo anterior. Si esta segunda terna fuera rechazada, ocupará el cargo la persona que dentro de dicha terna, designe el Presidente de la República".

Curiosamente hay un apartado que en su momento generó algunas suspicacias, no solo por su enunciado, sino porque dirían los que más saben, no ha lugar creo de que quedara señalado explícitamente, dice: “La remuneración que perciban por sus servicios los Ministros de la Suprema Corte...así como los Magistrados Electorales, no podrá ser disminuida durante su encargo". Ciertamente, es difícil que los salarios de los funcionarios bajen, no obstante, no hay necesidad de ser tan determinantes.

Y colocamos aquí también a los magistrados electorales, porque precisamente el artículo 99 señala: “El Tribunal Electoral será, con excepción de lo dispuesto en la fracción II del artículo 105 de esta Constitución, la máxima autoridad jurisdiccional en la materia y órgano especializado del Poder Judicial de la Federación". Funcionará en forma permanente con una Sala Superior y salas regionales. Integrándose la Sala Superior se integrará por siete Magistrados Electorales y corresponderá, entre otras “obligaciones": resolver en forma definitiva e inatacable:

a) Las impugnaciones en las elecciones federales de diputados y senadores.

b) Las impugnaciones sobre la elección de Presidente de los Estados Unidos Mexicanos que serán resueltas en única instancia por la Sala Superior.

\section{DE LA INSEGURIDAD, SU COMBATE Y “LA CORRUPCIÓN”}

Pero estos "contrapesos" son todavía más preocupantes, cuando en el artículo 102 se señala, apartado A: El Ministerio Público de la Federación se organizará en una Fiscalía General de la República como órgano público autónomo (que vendría a suplir a la Procuraduría General de la República, reformas del 10 de febrero de 2014, precisamente en la idea de darle autonomía a la justicia mexicana), dotado de personalidad jurídica y patrimonio propio. Durará en su encargo nueve años y, será designado y removido conforme a lo siguiente: a partir de la ausencia definitiva del Fiscal General, el Senado de la República contará con veinte días para integrar una lista de al menos diez candidatos al cargo, aprobada por las dos terceras partes de los miembros presentes, la cual enviará al Ejecutivo Federal. Recibida la lista, dentro de los diez 
días siguientes el Ejecutivo formulará una terna y la enviará a la consideración del Senado. El Senado, con base en la terna y previa comparecencia de las personas propuestas, designará al Fiscal General con el voto de las dos terceras partes de los miembros presentes dentro del plazo de diez días. Si el Senado no hace la designación, el Ejecutivo designará al Fiscal General. Por si hubiera duda, el párrafo IV señala: el Fiscal General podrá ser removido por el Ejecutivo Federal.

Ahora bien, pero esto se transforma todavía más significativo, por lo que se mencionará más adelante.

En el párrafo $B$, de este mismo artículo, se señala: “el Congreso de la Unión y las legislaturas de las entidades federativas, en el ámbito de sus respectivas competencias, establecerán organismos de protección de los derechos humanos". Ésta o éstas, tendrán un Consejo Consultivo integrado por diez consejeros que serán elegidos por el voto de las dos terceras partes de los miembros presentes de la Cámara de Senadores (o de los Diputados en el caso de las legislaturas locales) o, en sus recesos, por la Comisión Permanente del Congreso de la Unión, con la misma votación calificada. Pudiendo formular recomendaciones públicas, (pero) no vinculantes.

Y respecto a las responsabilidades de los servidores públicos (Artículo 108) se indica: el Presidente de la República, durante el tiempo de su encargo, sólo podrá ser acusado por traición a la patria y delitos graves del orden común. Por su parte, los servidores públicos están obligados a presentar, bajo protesta de decir verdad, su declaración patrimonial y de intereses ante las autoridades competentes y en los términos que determine la ley. Las faltas administrativas graves serán investigadas y substanciadas por la Auditoría Superior de la Federación de la Cámara de Diputados y los órganos internos de control internos y del Ejecutivo, o por sus homólogos en las entidades federativas, según corresponda, y serán resueltas por el Tribunal de Justicia Administrativa (designados por el Presidente de la República, con el voto de las dos terceras partes del Senado de la República y, su Presidente, directamente por el Ejecutivo, Art. 43, Ley Orgánica del Tribunal Federal de Justicia Administrativa).

Todos podrán ser sujetos de juicio político (artículo 110) pero, las declaraciones y resoluciones de las Cámaras de Diputados y Senadores, órganos competentes, son inatacables. Por lo que si ésta fuese negativa (artículo 111), se suspenderá todo procedimiento ulterior. Por lo que toca al Presidente, sólo habrá lugar a acusarlo (y juzgarlo) ante la Cámara de Senadores (procediendo en el mismo sentido). 
Lo que es más, el Procedimiento de juicio político sólo podrá iniciarse durante el período en el que el servidor público desempeñe su cargo y dentro de un año después (artículo 114). Bajo este contexto, ¿qué sucede o sucederá con nuestra democracia en los próximos años?

\section{DEL SISTEMA NACIONAL "ANTICORRUPCIÓN" Y EL MEJORAMIENTO DE LA DEMOCRACIA}

Con las reformas a la "justicia mexicana" de 2014, que crearía entre otras cosas, la Fiscalía General de la República ya comentada, se contempló la instalación del Sistema Nacional Anticorrupción (artículo 113), que entraría en vigor, el 19 de agosto de 2017, para ser exactos, hoy estamos a 17, que, de acuerdo a su conformación, será la instancia de coordinación entre las autoridades de todos los órdenes de gobierno competentes en la prevención, detección y sanción de responsabilidades administrativas y hechos de corrupción, así como en la fiscalización y control de recursos públicos cosa que, ya de entrada, pone en tela de juicio la función de los que ya estaban, en todo caso, porque no quitarlos.

Más ese no es el principal problema sucede que, para el cumplimiento de su objeto, señala: Contará con un Comité Coordinador que estará integrado por los titulares de la Auditoría Superior de la Federación; de la Fiscalía Especializada en Combate a la Corrupción; de la secretaría del Ejecutivo Federal responsable del control interno; por el presidente del Tribunal Federal de Justicia Administrativa; el presidente del "organismo garante" que establece el artículo $6^{\circ}$ de esta Constitución (ampliamente comentado); así como por un representante del Consejo de la Judicatura Federal y, tal vez lo novedoso, otro del Comité de Participación Ciudadana, que pasaría a ser el Presidente del Organismo.

Este Comité de Participación Ciudadana, se integrará o deberá integrarse por cinco ciudadanos, electos por el Senado, que se hayan destacado por su contribución a la transparencia, la rendición de cuentas o el combate a la corrupción (Ley Nacional Anticorrupción Artículo 18); éste Comité ya fue integrado, por lo que pareciera ya quedó resuelto, pero no; sucede, que donde se ha atorado la designación o conformación, es en el nombramiento del Fiscal o, del representante de la Fiscalía Especializada de Combate a la Corrupción, que la Ley marca, ciertamente, deberá ser designado por vez primera por el Senado, pero a partir del 30 de noviembre del año que entra, 2018, último día del Presidente de la República en funciones, podrá ser ya nombrado directamente por el Fiscal de la República.

Cuál es el problema? sucede, que como se vio en el artículo 102, ya comentado, cuando éste, el fiscal de la República, no es posible designarlo, conforme lo marca la Ley, por 
"acuerdo" del Senado, podrá nombrarlo directamente el Presidente de la República, incluso, pudiendo darle "paso automático" al actual Procurador, quien estaría por cierto, 9 años en el cargo, cosa que: 1) permitirá nombrar directamente al siguiente fiscal “anticorrupción”, ya sin la aprobación del Senado, justo cuando el actual Presidente deje el cargo y 2) por cierto, no hay que olvidar el artículo 114, el juicio político solo procede una vez dejado el cargo y dentro del año siguiente. ¿Es una coincidencia?

Dicho sea de paso, la propia ley constitucional señala (artículo 113): el carácter principal del SNA, corresponderá al Comité Coordinador del Sistema y tendrá dentro de sus facultades:

a) El establecimiento de mecanismos de coordinación con los sistemas locales.

b) El diseño y promoción de políticas integrales en materia de fiscalización y control de recursos públicos, de prevención, control y disuasión de faltas administrativas y hechos de corrupción.

c) La determinación de los mecanismos de suministro, intercambio, sistematización y actualización de la información que sobre estas materias generen las instituciones competentes de los órdenes de gobierno.

d) El establecimiento de bases y principios para la efectiva coordinación de las autoridades de los órdenes de gobierno en materia de fiscalización y control.

e) La elaboración de un informe que contenga los avances y resultados del ejercicio de sus funciones y de la aplicación de políticas y programas (pero que cree),

Derivado de este informe, podrá emitir recomendaciones, no vinculantes a las autoridades.

Es decir, todo queda igual, señalándose además: las entidades federativas establecerán sistemas (iguales) locales anticorrupción, con el objeto de coordinar a las autoridades locales competentes en la prevención, detección y sanción de responsabilidades administrativas y hechos de corrupción.

\section{CONCLUSIONES}

Como puede advertirse, la Constitución Política e instituciones mexicanas están lejos de ser o poder garantizar un Estado democrático, si bien es cierto, contienen algunas prácticas y clausulados con ciertos "fines democráticos", en el fondo y su instrumentación, respecto a los "requerimientos" que para tal efecto señalan Diamond y Morlino (2004) no pueden garantizarla 
sino se retiran o adecuan las facultades “metaconstitucionales” (Carpizo, 1978) del ejecutivo; ciertamente, esto tampoco garantizará per sé que la democracia suceda, sobre todo, porque como se señaló también ya en trabajos anteriores (Rodríguez Edeza, 2016 y 2017b), faltará ver si la cultura política mexicana también está preparada para ello, no obstante, será necesario dar el primer paso.

\section{REFERENCIAS}

ALCÁNTARA, Manuel, (2008). La calidad del liderazgo político en países andinos. Conferencias Magistrales. Partidos políticos y calidad de la democracia. Seminario Internacional. México. IFE. p. 59-91

CARPIZO, Jorge, (1978), El presidencialismo mexicano, México, Siglo XXI.

Cosío, Daniel Villegas, (1973), El sistema político mexicano, México, Cuadernos de Joaquín Mortiz.

DIAMOND Larry y Leonardo Morlino (2004), “The Quality of Democracy. An overview”, en Journal of Democracy, 15 (4), 20-31.

DAHL, Robert, (2003), ¿Es democrática es la Constitución de los Estados Unidos?, FCE, México.

RODRÍGUEZ EDEZA, Manuel A., (2016), “La relación entre el conocimiento político y la democracia. Una aportación desde el Estado de Sinaloa, México. El saber político”, Brasil, en Revista Debates, 10 (2), 149-170.

RODRÍGUEZ EDEZA, Manuel A., (2017), “México: la construcción fallida de un Estado y las nuevas reformas políticas”, Brasil, en Revista Debates, UFRGS: 11 (1), 159-182.

RODRÍGUEZ EDEZA, Manuel A., (2017b) "Un nuevo índice para medir la calidad de las democracias: el aspecto cognitivo o de capacidad", en Revista De Política de la Asociación Mexicana de Ciencia Política (AMECIP), Año 5, No. 8, Enero-Junio 2017, México.

RODRÍGUEZ EDEZA Manuel A., (2018), "Una nueva forma de medir la calidad de las democracias: el aspecto constitucional o legal”, Brasil, en Revista Debates, UFRGS: 12 (1), 61-86.

KRAUZE, Enrique (1994), Siglo de caudillos, en. México, Tusquets. 1994.

SARTORI, Giovanni, (2000), Partidos y sistemas de partidos. Madrid, Alianza Editorial.

MORLINO, Leonardo, $(2007,2008)$, “Calidad democrática entre líderes y partidos”, Conferencias Magistrales, Partidos políticos y calidad de la democracia, Seminario Internacional, México, IFE, p. $11-56$

VARGAS Llosa, “Encuentro vuelta”, 30 de agosto de 1990. En: https://www.youtube.com/watch?v=kPsVVWg-E38 


\section{ANEXO}

\section{VALORACIÓN DE MÉXICO RESPECTO A LAS DIMENSIONES DE CALIDAD DEMOCRÁTICA CONSIDERADOS POR DIAMOND Y MORLINO}

\begin{tabular}{|c|c|c|}
\hline $\begin{array}{l}\text { PAIS/ } \\
\text { VARIABLE }\end{array}$ & MÉXICO & OBSERVACIONES \\
\hline PROCEDIMIENTO & CONSTITUCIÓN & COMENTARIOS \\
\hline Estado de derecho & $\begin{array}{l}\text { Artículo } \mathbf{1}^{\circ} \text {. En los Estados Unidos Mexicanos todas las personas } \\
\text { gozarán de los derechos humanos reconocidos en esta } \\
\text { Constitución. } \\
\text { Queda prohibida toda discriminación. } \\
\text { Artículo 14. A ninguna ley se dará efecto retroactivo. } \\
\text { Artículo } 96 \text {. Para nombrar a los Ministros de la Suprema Corte de } \\
\text { Justicia, el Presidente de la República someterá una terna a } \\
\text { consideración del Senado. }\end{array}$ & $\begin{array}{l}\text { Hay aparente estado de } \\
\text { derecho }\end{array}$ \\
\hline Participación & $\begin{array}{l}\text { Artículo 35. Son derechos del ciudadano: } \\
\text { I. Votar en las elecciones populares; } \\
\text { II. Poder ser votado para todos los cargos de elección popular; } \\
\text { III. Asociarse individual y libremente para tomar parte en forma } \\
\text { pacífica en los asuntos políticos del país; } \\
\text { VII. Iniciar leyes, } \\
\text { VIII. Votar en las consultas populares sobre temas de } \\
\text { trascendencia nacional. }\end{array}$ & $\begin{array}{l}\text { Hay posibilidad de } \\
\text { participación (no directa). }\end{array}$ \\
\hline $\begin{array}{l}\text { Competencia } \\
\text { partidaria }\end{array}$ & $\begin{array}{l}\text { Artículo 41. Los partidos políticos son entidades de interés } \\
\text { público. } \\
\text { La ley garantizará que cuenten de manera equitativa con } \\
\text { elementos para llevar a cabo sus actividades. } \\
\text { III. Los partidos políticos nacionales y candidatos independientes } \\
\text { tendrán derecho al uso de manera permanente de los medios de } \\
\text { comunicación social. } \\
\text { e) El tiempo establecido como derecho de los partidos y de los } \\
\text { candidatos independientes, se distribuirá conforme a lo siguiente: } \\
\text { el setenta por ciento será distribuido entre los partidos políticos } \\
\text { de acuerdo a los resultados de la elección para diputados } \\
\text { federales inmediata anterior y el treinta por ciento restante } \\
\text { dividido en partes iguales, de las cuales, hasta una de ellas podrá } \\
\text { ser asignada a los candidatos independientes en su conjunto; } \\
\text { f) A cada partido político nacional sin representación en el } \\
\text { Congreso de la Unión se le asignará solamente la parte } \\
\text { correspondiente al porcentaje igualitario. } \\
\text { En ningún momento podrán contratar, por sí o por terceras } \\
\text { personas, tiempos en cualquier modalidad de radio y televisión. } \\
\text { Artículo } 41 \text {. Apartado A. El Instituto Nacional Electoral es el } \\
\text { organismo público (en materia electoral). } \\
\text { Contará en su estructura con órganos de dirección, ejecutivos, } \\
\text { técnicos y de vigilancia. El Consejo General será su órgano } \\
\text { superior de dirección y se integrará por un consejero Presidente y } \\
\text { diez consejeros electorales, y concurrirán, con voz pero sin voto, } \\
\text { los consejeros del Poder Legislativo, los representantes de los } \\
\text { partidos políticos y un Secretario Ejecutivo; } \\
\text { El consejero Presidente y los consejeros electorales, serán electos } \\
\text { por el voto de las dos terceras partes de los miembros presentes } \\
\text { de la Cámara de Diputados. }\end{array}$ & $\begin{array}{l}\text { Hay una "diferenciada" } \\
\text { competencia partidaria, } \\
\text { aunque existe posibilidad } \\
\text { der candidaturas } \\
\text { independientes. }\end{array}$ \\
\hline $\begin{array}{l}\text { Rendición de } \\
\text { cuentas electoral }\end{array}$ & $\begin{array}{l}\text { Artículo } 71 \text {. El derecho de iniciar leyes o decretos compete: } \\
\text { IV. A los ciudadanos en un número equivalente, por lo menos, al }\end{array}$ & Hay elecciones recurrentes \\
\hline
\end{tabular}




\begin{tabular}{|c|c|c|}
\hline (vertical) & $\begin{array}{l}\text { cero punto trece por ciento de la lista nominal de electores. } \\
\text { Artículo } 41 \text {. La renovación de los poderes Legislativo y Ejecutivo } \\
\text { se realizará mediante elecciones libres, auténticas y periódicas. } \\
\text { Artículo } 51 \text {. La Cámara de Diputados se compondrá de } \\
\text { representantes de la Nación, electos en su totalidad cada tres } \\
\text { años. } \\
\text { Artículo } 56 \text {. La Cámara de Senadores se integrará por ciento } \\
\text { veintiocho senadores, de los cuales, en cada Estado, dos serán } \\
\text { elegidos según el principio de votación mayoritaria relativa y uno } \\
\text { será asignado a la primera minoría. Los treinta y dos restantes } \\
\text { serán elegidos según el principio de representación proporcional, } \\
\text { mediante el sistema de listas votadas en una sola circunscripción } \\
\text { plurinominal nacional. Se renovará en su totalidad cada } 6 \text { años. } \\
\text { Artículo } 81 \text {. La elección del Presidente será directa. } \\
\text { Artículo } 59 \text {. Los Senadores podrán ser electos hasta por dos } \\
\text { periodos consecutivos y los Diputados al Congreso de la Unión } \\
\text { hasta por cuatro. }\end{array}$ & \\
\hline $\begin{array}{l}\text { Rendición de } \\
\text { cuentas } \\
\text { interinstitucional } \\
\text { (horizontal) }\end{array}$ & 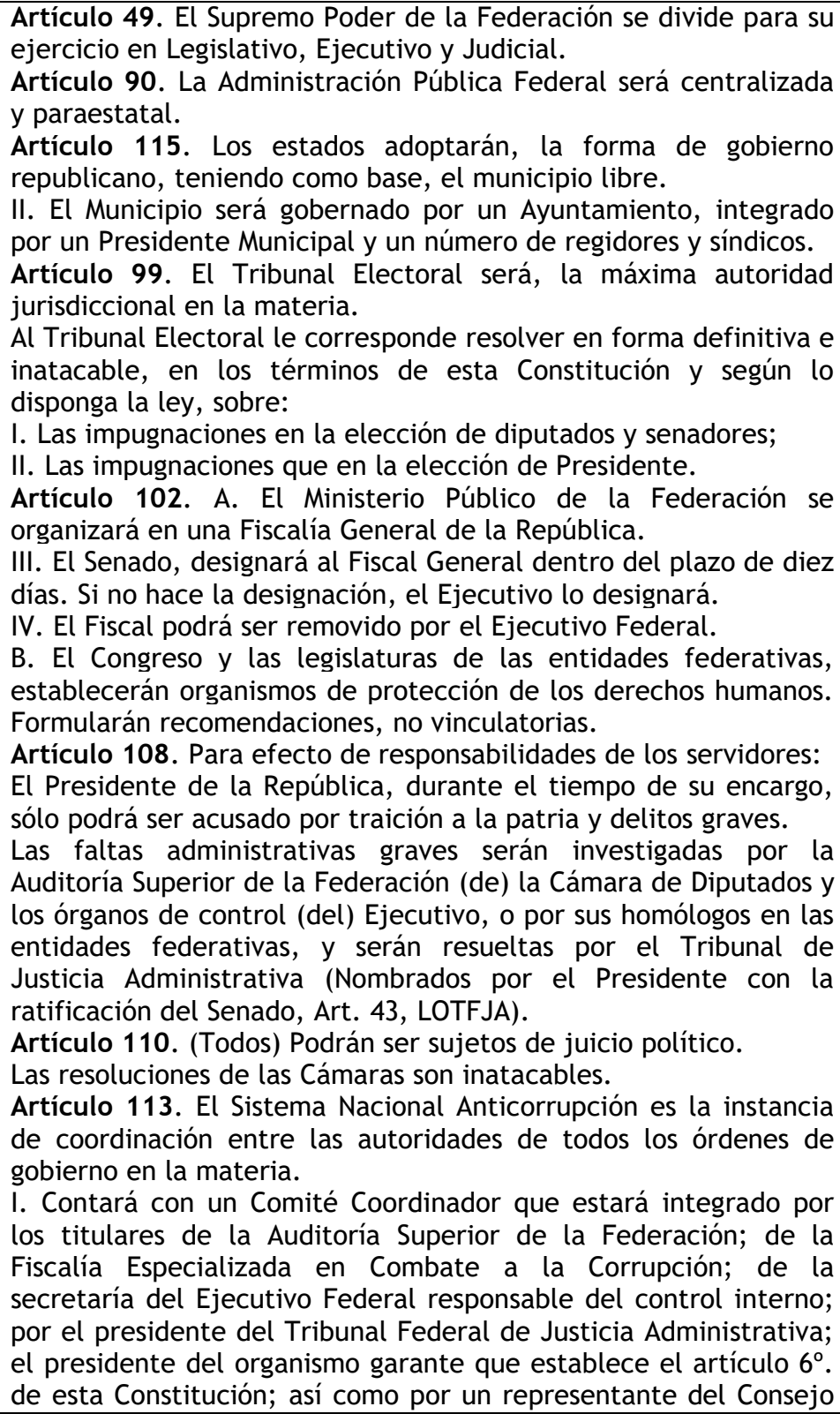 & $\begin{array}{l}\text { No hay pesos y contrapesos } \\
\text { claros }\end{array}$ \\
\hline
\end{tabular}




\begin{tabular}{|c|c|c|}
\hline & $\begin{array}{l}\text { de la Judicatura Federal y otro del Comité de Participación } \\
\text { Ciudadana; } \\
\text { II. El Comité de Participación Ciudadana del Sistema deberá } \\
\text { integrarse por cinco ciudadanos (electos por el Senado, Ley } \\
\text { Secundaria Art. 18). } \\
\text { III. Corresponderá al Comité Coordinador del Sistema (Principal), } \\
\text { en los términos que determine la Ley: } \\
\text { e) La elaboración de un informe que contenga los avances y } \\
\text { resultados del ejercicio de sus funciones y de la aplicación de } \\
\text { políticas y programas. No vinculantes. }\end{array}$ & \\
\hline CONTENIDO & CONSTITUCIÓN & COMENTARIOS \\
\hline Libertad & $\begin{array}{l}\text { Artículo 6o. La manifestación de las ideas no será objeto de } \\
\text { ninguna inquisición judicial o administrativa. } \\
\text { A. Para el ejercicio del derecho de acceso a la información, la } \\
\text { Federación y las entidades federativas, se regirán por los } \\
\text { siguientes principios y bases: } \\
\text { l. Toda la información, es pública y sólo podrá ser reservada } \\
\text { temporalmente por razones de interés público...la ley } \\
\text { determinará los supuestos específicos bajo los cuales procederá la } \\
\text { declaración de inexistencia de la información. } \\
\text { VIll. La Federación contará con un organismo autónomo } \\
\text { especializado. Sus resoluciones son vinculatorias, definitivas e } \\
\text { inatacables. } \\
\text { Se integrará por siete comisionados. La Cámara de Senadores } \\
\text { nombrará a los comisionados. El nombramiento podrá ser } \\
\text { objetado por el Presidente de la República. } \\
\text { B. En materia de radiodifusión y telecomunicaciones: } \\
\text { V. La ley establecerá un organismo público descentralizado con } \\
\text { autonomía técnica, operativa, de decisión y de gestión. } \\
\text { El organismo público contará con un Consejo Ciudadano. } \\
\text { Su Presidente será designado, a propuesta del Ejecutivo. }\end{array}$ & Hay una aparente libertad \\
\hline Igualdad & $\begin{array}{l}\text { Artículo } 2^{\circ} \text {. A. Esta Constitución reconoce y garantiza el derecho } \\
\text { de los pueblos indígenas a la libre determinación y, su } \\
\text { autonomía. } \\
\text { Artículo 5o. A ninguna persona podrá impedirse que se dedique a } \\
\text { la profesión, industria, o trabajo que le acomode, siendo lícitos. } \\
\text { Artículo } 1^{\circ} \text {. Las normas relativas a los derechos humanos se } \\
\text { interpretarán de conformidad con esta Constitución y con los } \\
\text { tratados internacionales de la materia favoreciendo en todo } \\
\text { tiempo a las personas la protección más amplia. }\end{array}$ & $\begin{array}{l}\text { Hay una posibilidad } \\
\text { igualitaria ante la ley }\end{array}$ \\
\hline RESULTADO & CONSTITUCIÓN & COMENTARIOS \\
\hline $\begin{array}{l}\text { Respuesta } \\
\text { (Responsiveness) }\end{array}$ & $\begin{array}{l}\text { Artículo 3o. Toda persona tiene derecho a recibir educación. } \\
\text { Artículo 4o. (...) Toda persona tiene derecho a la alimentación } \\
\text { nutritiva, suficiente y de calidad. El Estado lo garantizará. } \\
\text { Toda persona tiene derecho a la protección de la salud. } \\
\text { Toda persona tiene derecho a un medio ambiente sano para su } \\
\text { desarrollo y bienestar. El Estado garantizará. } \\
\text { Toda persona tiene derecho al acceso, disposición y saneamiento } \\
\text { de agua para consumo personal y doméstico en forma suficiente, } \\
\text { salubre, aceptable y asequible. El Estado garantizará. } \\
\text { Toda familia tiene derecho a disfrutar de vivienda digna. } \\
\text { Artículo } 123 \text {. Toda persona tiene derecho al trabajo digno; } \\
\text { XXIX. Será de utilidad pública la Ley del Seguro Social, y ella } \\
\text { comprenderá seguros de invalidez, de vejez, de vida, de cesación } \\
\text { involuntaria del trabajo, de enfermedades y accidentes, entre } \\
\text { otras. }\end{array}$ & Existen resultados en la ley \\
\hline
\end{tabular}




\section{COMO FAZER REFERÊNCIA AO ARTIGO (ABNT):}

RODRÍGUEZ EDEZA, Manuel Ángel. Los obstáculos de la constitución mexicana: un "autoritarismo democrático". Revista Eletrônica do Curso de Direito da UFSM, Santa Maria, RS, v. 14, n. 3, e37536, set./dez. 2019. ISSN 19813694. DOI: http://dx.doi.org/10.5902/1981369437536. Disponível em:

https: //periodicos.ufsm.br/revistadireito/article/view/37536 Acesso em: dia mês. ano.

Direitos autorais 2019 Revista Eletrônica do Curso de Direito da UFSM

Editores responsáveis: Rafael Santos de Oliveira e Angela Araujo da Silveira Espindola

\section{c) (†) $\odot$}

Este obra está licenciado com uma Licença Creative Commons Atribuição-NãoComercial-SemDerivações 4.0 Internacional.

\section{SOBRE O AUTOR}

\section{MANuel Ángel Rodríguez Edeza}

Doutor em Ciências Sociais pela Universidad Autónoma de Sinaloa. Economista y polítólogo, Profesor Investigador por la Universidad Autónoma de Occidente, México. 